\title{
Interlaminate Deformation in Thermoplastic Composite Laminates: Experimental-Numerical Correlation
}

\author{
Min SHEN ${ }^{1, a}$, Jingwei $\mathrm{TONG}^{1}$, Shibin $\mathrm{WANG}^{1}$, and Yihong Fang ${ }^{1}$ \\ ${ }^{1}$ Department of Mechanics, Tianjin University, Tianjin 300072, PR China
}

\begin{abstract}
The interlaminar deformation behaviors of thermoplastic AS4/PEEK composite laminates subjected to static tensile loading are investigated by means of microscopic moiré interferometry with high spatial resolution. The fully threedimensional orthotropic elastic-plastic analysis of interlaminar deformation for the thermoplastic laminates is developed in this paper, and used to simulate the stress-strain curves of tensile experiment for its angle-ply laminates. Under uniaxial tensile loading, the 3D orthotropic elastic-plastic FE analysis and microscopic moiré interferometry of interlaminar deformations are carried out for the $[ \pm 25]_{\mathrm{S} 4}$ laminates. The quantitative local-filed experimental results of interlaminar shear strain and displacements at freeedge surface of the laminate are compared with corresponding numerical results of the orthotropic elastic-plastic FE model. It is indicated that the numerical tensile stressstrain curves of angle-ply laminates computed with 3D orthotropic elastic-plastic model are agree with experimental results. The numerical interlaminar displacement $U$ and shear strain $\gamma_{x z}$ are also consistent with the experimental results obtained by moiré interferometry. It is expected the elastic-plastic interlaminar stresses and deformations analysis for the optimal design and application of AS4/PEEK laminates and its structures.
\end{abstract}

\section{INTRODUCTION}

AS4/PEEK laminates is a high-performance thermoplastic composite material which is now widely used in the aerospace industry [1]. Due to the ductility of matrix in AS4/PEEK laminates increase, the mechanical behaviours of full laminates have evidently plasticity.

The subject of free edge delamination of composite laminated plates, as one of the most frequently encountered types of failure in composite materials, has attracted considerable attention. A difficulty arises in quantifying the three-dimensional state of stress near a free-edge of the laminate. Since the original paper of Pipes and Pagano [2], numerous papers have been published on the subject over the years. They have included the finite difference solution of Pipes and Pagano, approximate analytical solution [3], finite element solution [4-6], and several experimental investigations [7-13]. A complete review can be found in Ref. [14]. The most of these researches including analyses and experiments are carried for thermoset composite laminates in linear elastic range. There are a few researches of the nonlinear behaviours and damage [15-20] for the

\footnotetext{
a e-mail : minshen@tju.edu.cn
} 
AS4/PEEK laminates. However, in contrast to the free edge problem of thermoset composite laminates, the understanding of the corresponding behaviour in thermoplastic AS4/PEEK composite laminates is virtually nonexistent. It is expected the elastic-plastic interlaminar stresses and deformation analysis for the optimal design and application of AS4/PEEK laminates and its structures.

In present work the interlaminar deformation of thermoplastic composite AS4/PEEK laminates subjected to static tensile loading are investigated by means of microscopic moiré interferometry and three-dimensional orthotropic elastic-plastic finite element (FE) method. The orthotropic linear hardening material model is selected to describe the elastic-plastic behaviour of anisotropy in its unidirectional AS4/PEEK laminate. The elastic-plastic finite element model of AS4/PEEK angle-ply laminates is developed. The interlaminar deformations and tensile behaviour of the laminates are simulated.

The intent of this paper is to present accurate experimental results for the interlaminar displacement and strain at free edge for the AS4/PEEK angle-ply laminates, and to compare the experimental results with above FE numerical results obtained using the three-dimensional orthotropic elastic-plastic model. Interlaminar deformations, such as shear strain and displacements, are emphasized because the moiré interferometry technique, which is used for the experimental measurements, provides displacements directly. The gradients of these displacements are the shear strains that can be compared with the strains obtained from the FE numerical solution. The comparisons between numerical and experimental results can verify the three-dimensional orthotropic elastic-plastic FE model of thermoplastic AS4/PEEK laminates. A second goal of this investigation is to gain a better understanding of the influence of PEEK matrix ductility on interlaminar elastic-plastic deformation in AS4/PEEK thermoplastic composite laminates.

\section{MATERIALS AND ITS ANISOTROPIC PLASTIC NUMERICAL MODEL}

\subsection{Material system}

The material system, AS4/PEEK, used in this study consisted of AS4 graphite fibers in PEEK matrix. It was supplied by Fiberite Corporation in the form of 16-ply $[ \pm 25]_{\mathrm{s} 4}$ stacking sequences laminates. The fibres content was 61.0 percent by volume. The main mechanical properties determined on unidirectional laminates by standard static tests are reported in Table 1.

Table 1. The mechanical properties of unidirectional AS4/PEEK

\begin{tabular}{ccccccccc}
\hline $\begin{array}{c}\mathbf{E}_{1} \\
(\mathbf{G P a})\end{array}$ & $\begin{array}{c}\mathbf{E}_{2}=\mathbf{E}_{3} \\
(\mathbf{G P a})\end{array}$ & $v_{12}=v_{13}$ & $v_{23}$ & $\begin{array}{c}\mathbf{G}_{12}=\mathbf{G}_{13} \\
(\mathbf{G P a})\end{array}$ & $\begin{array}{c}\mathbf{G}_{23} \\
(\mathbf{G P a})\end{array}$ & $\begin{array}{c}\mathbf{X} \\
(\mathbf{M P a})\end{array}$ & $\begin{array}{c}\mathbf{Y} \\
(\mathbf{M P a})\end{array}$ & $\begin{array}{c}\mathbf{S} \\
(\mathbf{M P a})\end{array}$ \\
\hline & & & & & & & & \\
134 & 10 & 0.3 & 0.47 & 5.6 & 3.38 & 2200 & 88 & 68 \\
\hline
\end{tabular}

\subsection{D orthotropic elastic-plastic finite element models}

Assuming that the AS4/PEEK lamina is a homogenous, orthotropic and elastic-plastic continuum. The elastic-plastic behaviour of anisotropy in its unidirectional laminate is described using the orthotropic linear hardening.

The constitutive of anisotropic plasticity of AS4/PEEK uses Hill's yield criterion, which accounts for differences in yield strength in orthogonal directions, as modified by Shih and Lee [21], accounting for differences in yield strength in tension and compression. An associated flow rule is assumed and work hardening as presented by Valliappan et al. is used to update the yield criterion [22]. Based on the mechanical-properties of AS4/PEEK tested by Martin etc. [16], the orthotropic 
parameters of linear hardening of AS4/PEEK were determined by means of analysis of its orthotropic property in present work.

\subsection{Finite element model of as4/peek laminates}

Consider the rectangular, symmetric angle-ply laminate shown in Fig. 1. It has sixteen plies, each of thickness $\mathrm{h}$, and is loaded with a uniform axial strain $\varepsilon_{0}$ in the $\mathrm{x}$-direction.

For $[ \pm 25]_{\mathrm{s} 4}$ angle-ply laminate, it has a symmetry with respect to the $\mathrm{x}-\mathrm{y}$ plane at $\mathrm{z}=0$. Therefore, the analysis has been executed only for the upper half of the laminate. Thus it has eight plies. The length and width of the laminate are $2 \mathrm{a}$ and $2 \mathrm{~b}$, respectively, with $\mathrm{a}=\mathrm{b}=1.75 \mathrm{~mm}$, where the ply thickness $h=0.1275 \mathrm{~mm}$, as shown in Fig.1. In such a case, the displacement boundary conditions are

$$
\begin{aligned}
& u(0, y, z)=0, \\
& u(2 a, y, z)=2 a \varepsilon_{0}, \\
& v(a, 0,0)=0, \\
& w(x, y, 0)=0 .
\end{aligned}
$$

The isoparametric eight-node block element is employed to calculate the model. There are 20 elements in the x-direction that is equally divided 24 elements in the y-direction and they are gradually refined to the edge in the $y$ - and z-directions. There are 9920 elements and 11613 nodes in all.

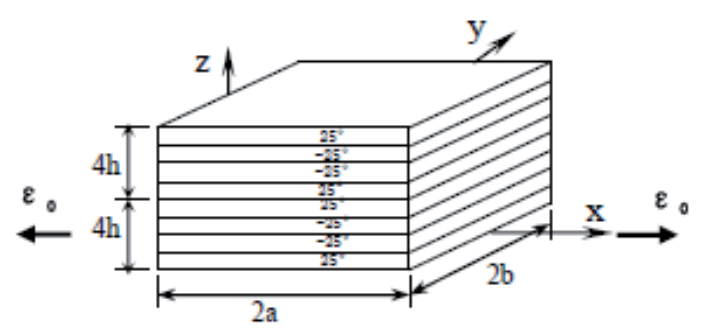

Fig. 1 Finite element model for the upper half of the $[ \pm 25]_{\mathrm{s} 4}$ laminated rectangular plate subjected to a uniform axial strain $\varepsilon_{0}$

\section{EXPERIMENTAL PROCEDURES}

The specimens are laminates of AS4/PEEK with approximately 134-mm long, 3.0-mm wide and 2.04-mm thick. The tensile loads were from low to high, generating axial strains typically ranging about 1.10 percent for these laminates. Specimen heads were reinforced by aluminum tabs $1.0 \mathrm{~mm}$ thick bonded by epoxy resin depicted in Fig.2. The axial tensile strain $\varepsilon_{0}$ is measured by the strain gage that adhered to the face of the specimen.

A high frequency reflection crossed-line grating of 1208 lines/mm was applied to the edge surface of the specimen by a replication process. Its sensitivity is in the subwavelength range, viz. $0.417 \mu \mathrm{m}$ per fringe order, using a reference grating of 2416 lines $/ \mathrm{mm}$. Microscopic moiré interferometry developed in this work is an optical system that combines a four-beam moiré interferometry with a long distance microscope (LDM) as shown in Fig.3. It effectively enhances the spatial resolution of the usual moiré interferometry and can be able to measure real-time the micromechanical behaviour of the small deformation field on the free edge of a loaded laminate. 


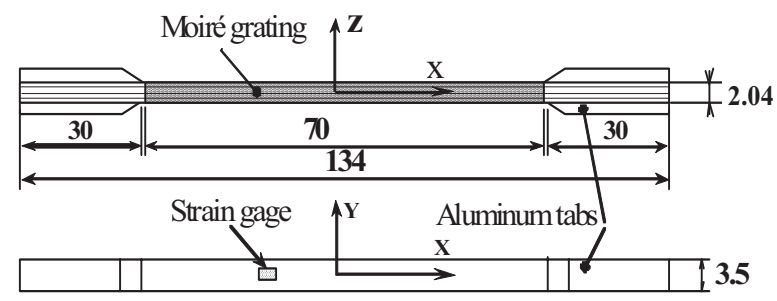

Fig. 2 AS4/PEEK laminate specimen geometry (mm)

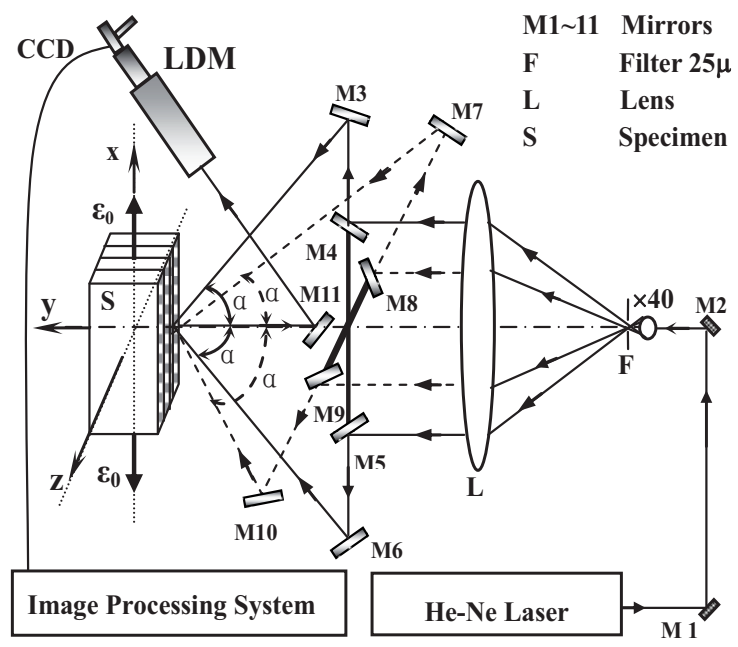

Fig. 3 Optical paths and arrangement for LDM four-beam moiré interferometry

\section{RESULTS AND DISCUSSION}

\subsection{D orthotropic elastic-plastic FE-simulation of AS4/PEEK tensile curves and its experimental verification}

The one-parameter orthotropic plasticity model was introduced by Sun and Chen (1989) [23], to describe the nonlinear behavior of orthotropic fiber-reinforced composite materials. Based on the assumption that plastic deformation in the fiber direction is negligible, the plastic potential function for an orthotropic layer under plane-stress conditions reduces to the form

$$
2 f=\sigma_{2}^{2}+2 a_{66} \tau_{12}^{2}
$$

where 1 is the fiber direction and 2 is the transverse direction. The single plastic parameter $a_{66}$ is the material constant found from off-axis tension.

Fig. 4 shows the predictions of the stress/strain response of representative AS4/PEEK angle-ply specimens obtained from both the present 3D orthotropic elastic-plastic FE model and the oneparameter orthotropic plasticity FE model by Meili and Priolo [24]. Comparing with experimental 
dates, the predictions of the present model are shown to agree fairly well the experimental results over a wide range of loading levels for various AS4/PEEK angle-ply laminates.

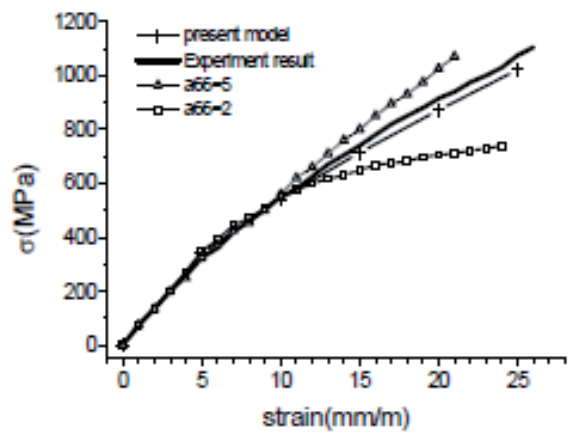

(1) $[ \pm 25]_{4 \mathrm{~s}}$

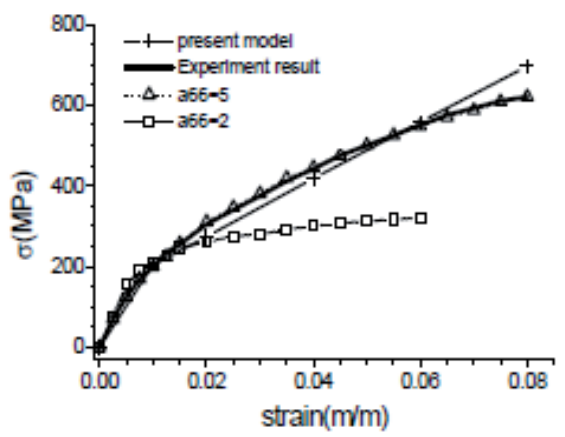

(1) $[ \pm 35]_{4 \mathrm{~s}}$

Fig. 4 Comparison of numerical predictions of present orthotropic elasto-plastic FE model and oneparameter model by Meili and Priolo with experimental dates for tension tests

\subsection{D orthotropic elastic-plastic interlaminar deformations and their experimental verification}

Fig. 5(1) shows the moiré fringe patterns of interlaminar displacement $U$ field for AS4/PEEK [ \pm $25]_{\mathrm{s} 4}$ laminate under axial tensile loading. The distributions of $U$ and shear strain obtained from the FE model are given in Figs. 5(2) and (3).

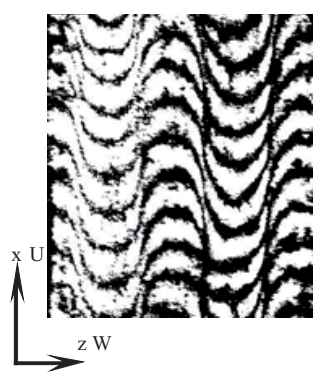

(1) The fringe patterns

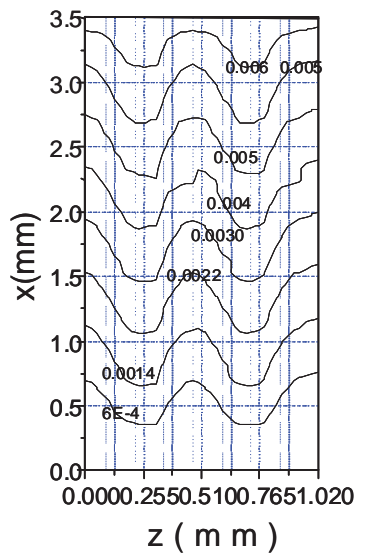

(2) U displacement of FE

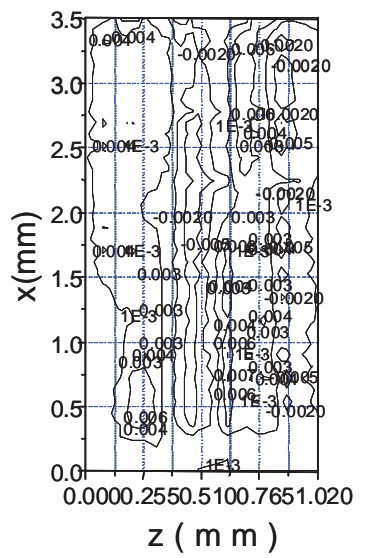

(3) shear strain $\gamma_{x z}$ of FE

Fig. 5 The interlaminar deformation at the free edge of the $[ \pm 25]_{s 4}$ laminated rectangular plate subjected to a uniform axial strain $\varepsilon 0$ (1)The moiré fringe patterns of $U$ field , (2) U displacement and (3) shear strain $\gamma_{x z}$ distribution obtained from the FE model.

Fig.6(1) shows the moiré fringe patterns of interlaminar displacement $U$ field for $[ \pm 25]_{\mathrm{s} 4}$ laminate under axial tensile loading. Experimental and numerical distributions of interlaminar displacement $u$ and shear strain $\gamma_{x z}$ on free edge of $[ \pm 25]_{S 4}$ laminate are given in Fig.6(2) and (3) while axial tensile loading $\mathrm{P}$ is $882 \mathrm{~N}$. It is found that interlaminar shear strain $\gamma_{\mathrm{xz}}$ is very large, and achieves its maximal values near four interfaces between \pm 25 plies. The numerical interlaminar displacement $u$ 
and shear strain $\gamma_{\mathrm{xz}}$ are also consistent with the experimental results obtained by moiré interferometry, especially shear strain concentrations near the interfaces between \pm 25 plies at the edge of the laminate. Comparison of the FE numerical and experimental results indicates that the 3D orthotropic elastic-plastic FE analysis for interlaminar deformations of AS4/PEEK composite is reliable and validity, and can fairly reflect influence of ductility of PEEK matrix on the elasticplastic behaviour of whole AS4/PEEK laminate.
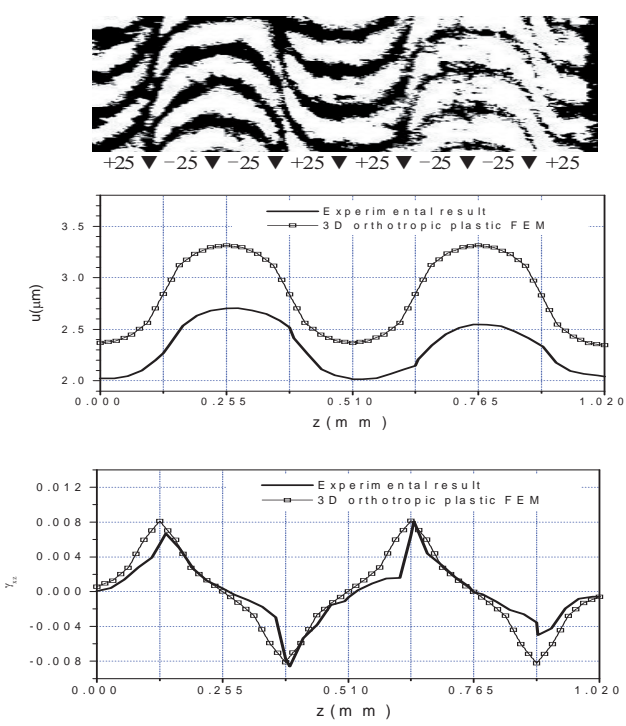

Fig. 6 Interlaminar deformations of $[ \pm 25]_{s 4}$ laminate loaded at $882 \mathrm{~N}$

(1) U Fringe Patterns, $\boldsymbol{\nabla}$ Actual Ply Boundaries

(2) experimental vs numerical interlaminar displacement $u$

(3) experimental vs numerical interlaminar shear strain $\gamma_{x z}$

\section{CONCLUSIONS}

1. The interlaminar deformation behaviors of thermoplastic AS4/PEEK composite laminates subjected to static tensile loading are investigated by means of microscopic moiré interferometry with high spatial resolution.

2. Based on the mechanical-properties of AS4/PEEK tested by Martin etc., the orthotropic parameters of linear hardening of its laminar were determined by means of analysis of its orthotropic property in this work. Using Shih's theory of anisotropic plasticity its elasticplastic behavior of anisotropy was described in this paper.

3. A three-dimensional orthotropic elastic-plastic finite element model of AS4/PEEK laminates is developed, and used to simulated the stress-strain curves of tensile experiment for the angle-ply laminates. The numerical tensile stress-strain curves of the laminates computed with 3D orthotropic elastic-plastic model are agreed with experimental results.

4. Under uniaxial tensile loading, the 3D orthotropic elastic-plastic FE analysis of interlaminar deformations are carried out for $[ \pm 25]_{\mathrm{s} 4}$ laminate.

5. It is obvious that comparing between numerical and experimental results, the nonlinear stress-strain behavior of AS4/PEEK laminates can be predicted using the orthotropic elastic-plastic FE model. This comparison also indicates that the 3D orthotropic elasticplastic FE analysis for interlaminar deformations of AS4/PEEK composite is reliable, and can fairly reflect influence of ductility of PEEK matrix on the elastic-plastic behavior of 
whole AS4/PEEK laminate.

Acknowledgements: The authors gratefully acknowledge the financial support of the present work by the National Natural Science Foundation of China (No.10972155, 10972156 and 10572103).

\section{References}

1. F N Cogswell, Theromplastic Aromatic Polymer Composites, Technomic Publishing Co., Inc. (1992).

2. R B Pipes, Pagano, N.J. Interlaminar Stresses in Composite Laminates under Uniform Axial Extension, J. Composite Materials, 4: 538-548 (1970).

3. N J Pagano. Free-Edge Stress Fields in Composite Laminates. Int. J. Solids Structures, 14: 401406 (1978).

4. G. Isakson, A. Levy, Finite-element analysis of interlaminar shear in fibrous composites. J. Comp .Mat. 5: 273-276 (1971).

5. A.S.D. Wang, F.W. Crossman, Some new results on edge effects in symmetric composite laminates. J. Comp.Mat. 11: 92-106 (1977).

6. R.L. Spilker, A traction-free-edge hybrid-stress element for the analysis of edge effects in crossply laminates. Comp. Struct. 12: 167-179 (1980).

7. R.B. Pipes, I.M. Daniel, Moiré analysis of the Interlaminar shear edge effect in laminated composites. J. Comp. Mat. 5: 255-259 (1971).

8. Fulong Dai, D. Post, Yinyan Wang, Residual Thermal strains in a laminated composite, 7th Inter. Conf. on Comp. Material, Beijing, China (1989).

9. G. Ragmond, D. Post, Interlaminar Deformation on the Boundary Surface of a hole in thick composite, SEM: 346 (1989).

10. D. Post, Moiré Interferometry for Damage Analysis of Composites, Exp. Tech. 17: 20 (1983).

11. C.T. Herakovich, D. Post, M.B. Buczek, R. Czarnek, Free Edge Strain Concentrations in Real Composite Laminates: Experimental-Theoretical Correlation, Journal of Applied Mechanics, 52: 787-793 (1985).

12. D. Post, Experimental Analysis of Composites by Moiré Interferometry, Procs. Int. Seminar on Experimental Techniques and Design in Composite Materials, Cagliari: 285-295 (1992).

13. D. Post, Fulong Dai, Y.Y. Wang, Interlaminar Compression of Thick Composites. SEM (1989).

14. T Kant, K Swaminathan, Compos Struct, 49: 65 (2000)

15. K.J.Yoon and C.T.Sun, Journal of Composite Materials, 25: 1277 (1991)

16. R.J.Martin, R.S Sandhu, A.N.Palazotto, Experimental and Analytical Comparisons of Failure in Thermoplastic Composite Laminates, Experimental Mechanics, 18: 53-65 (1994).

17. F. Aymerich, P. Priolo. Damage in Graphite-Peek Angle-Ply Laminates, Procs. Int. Seminar on Experimental Techniques and Design in Composite Materials, Cagliari: 153-163 (1992).

18. M.C. Lafarie-Frenot, F. Touchard, Comparative In-plane Shear Behaviour of Long-carbon-Fiber Composites with Thermoset or Thermoplastic Matrix. Composites Science and Technology, 52: 417-425 (1994).

19. Touchard-Lagattu,F. and Lafarie-Frenot, M.C., Damage and Inelastic Deformation Mechanisms in Notched Thermoset and Thermoplastic Laminates. Composites Science and Technology, 56:557-568, 1996.

20. F. Aymerich, P. Priolo, Static and Fatigue Strength of Notched Graphite-Peek Angle-Ply Laminates, Advancing with Composites: 83-91 (1994).

21. C.F. Shih, D. Lee, Further Developments in Anisotropic Plasticity. Journal of Engineering Materials and Technology, 100: 294-302 (1978).

22. S. Valliappan, P. Boonlaulohr, I.K. Lee. Non-Linear Analysis for Anisotropic Materials. Int J for Numerical Methods in Engineering, 10: 597-606 (1976).

23. C.T. Sun, J.L. Chen, Journal of Composite Materials, 23: 1009-1020 (1989).

24. S. Meili, P. Priolo, Experimental Techniques and Design in Composite Materials 3: (1996). 